\title{
Xenibellols A and B, Novel Diterpenoids from the Formosan Soft Coral Xenia umbellata
}

\author{
Ali A. H. El-Gamal, Shang-Kwei Wang, and Chang-Yih Duh ${ }^{\star}$ \\ Department of Marine Resources, National Sun Yat-sen University, \\ Kaohsiung, Taiwan, Faculty of Pharmacy, Mansoura University, Egypt, Graduate \\ Institute of Medicine, Kaohsiung Medical University
}

\section{List of Supporting Information:}

(1) ${ }^{1} \mathrm{H}$ NMR and ${ }^{13} \mathrm{C}$ NMR spectra of 1

(2) ${ }^{1} \mathrm{H}$ NMR and ${ }^{13} \mathrm{C}$ NMR spectra of 2 


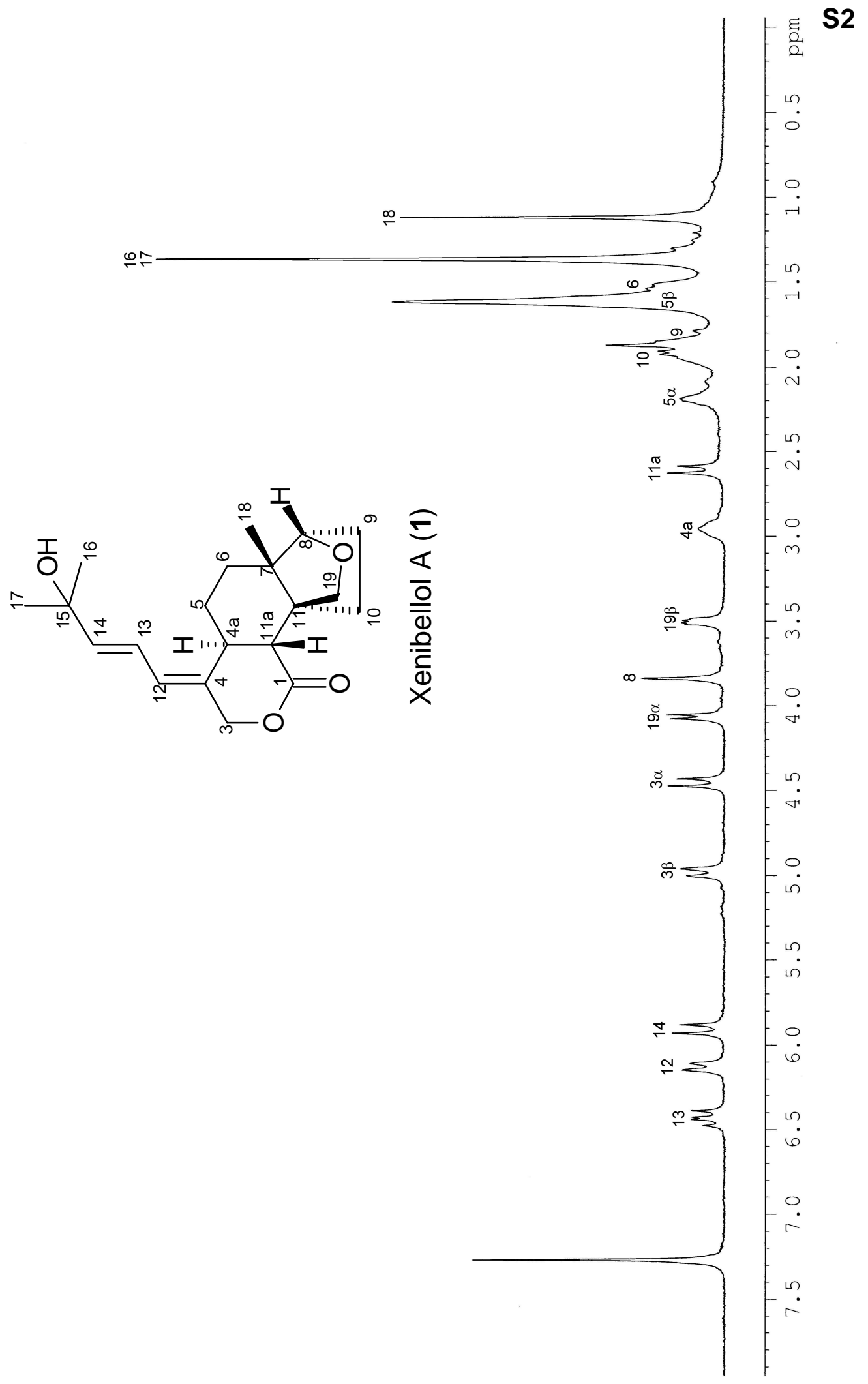




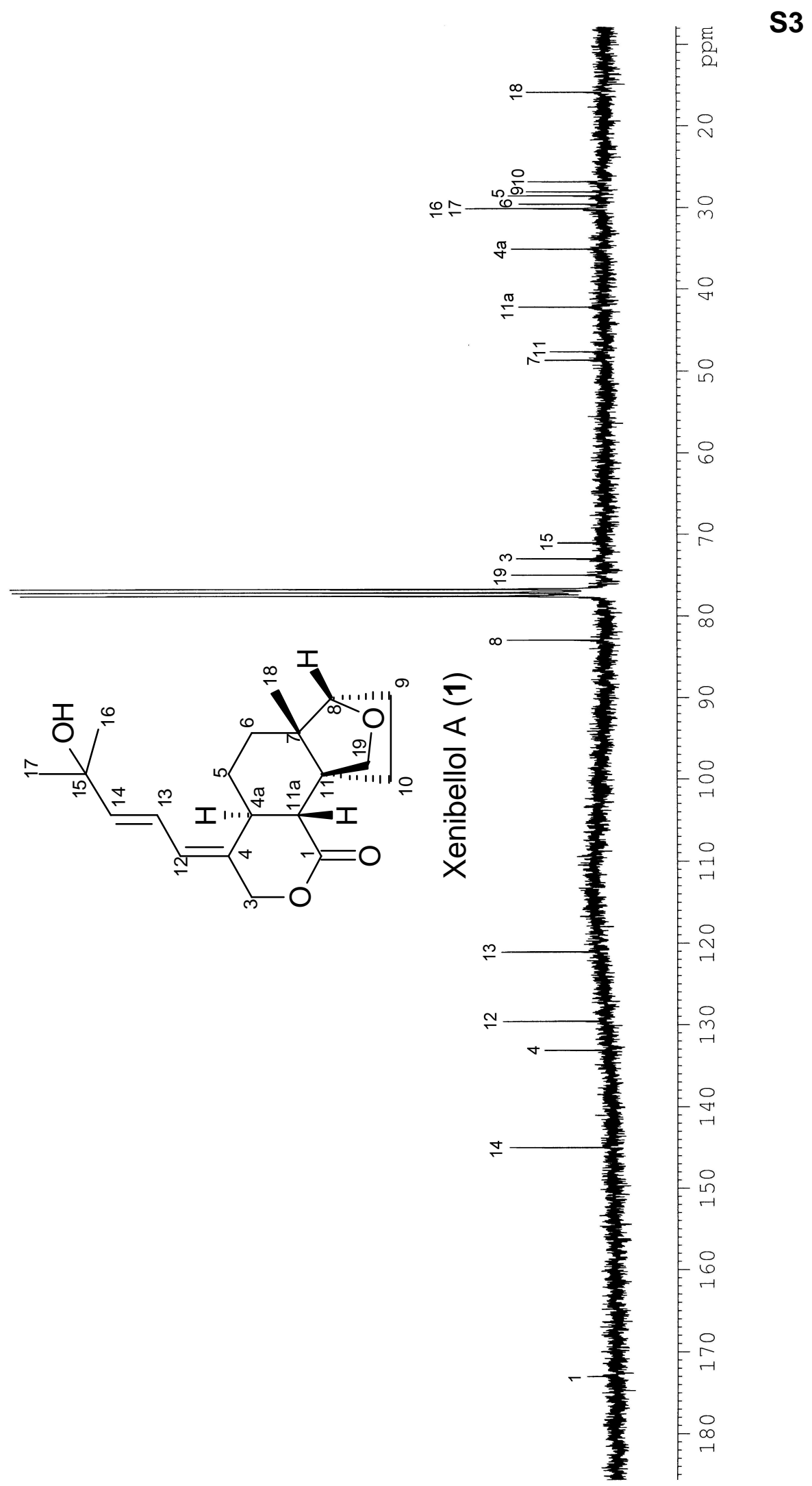




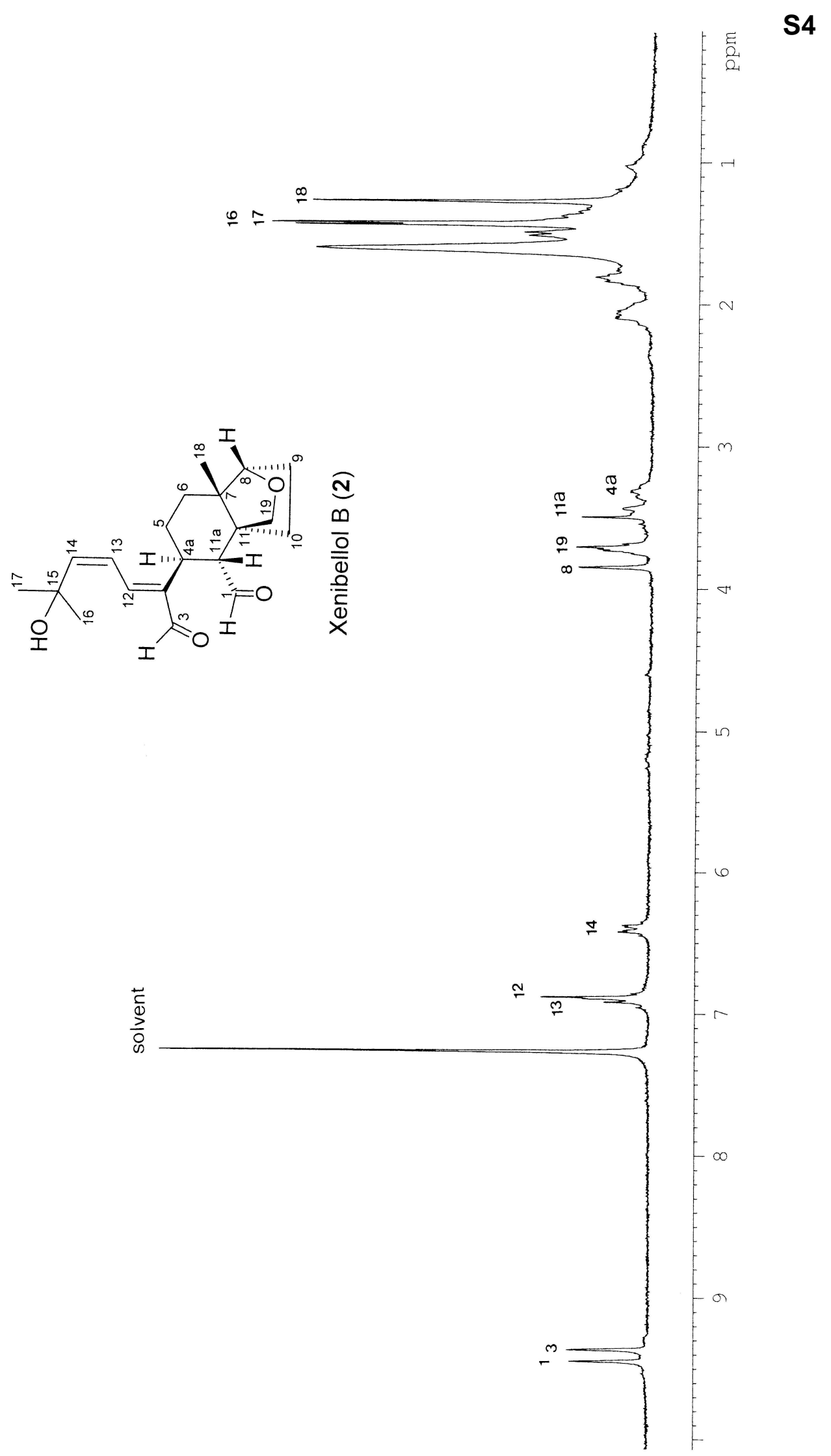




$$
\|
$$

